\title{
Spatial-Temporal Distribution and Characteristics of Internal Waves in the Lombok Strait Area Studied by Alos-Palsar Images
}

\author{
I Wayan Gede Astawa Karang ${ }^{1,2}$, Fumihiko Nishio ${ }^{1}$, Leonid Mitnik ${ }^{3} \&$ Takahiro Osawa $^{2}$ \\ ${ }^{1}$ Center for Environmental Remote Sensing, Chiba University, Yayoi, Inage, Chiba, Japan \\ ${ }^{2}$ Center for Remote Sensing and Ocean Science (CReSOS), Udayana University, Denpasar, Bali, Indonesia \\ ${ }^{3}$ V.I. Il'ichev Pacific Oceanological Institute FEB RAS, Vladivostok, Russian Federation \\ Correspondence: I Wayan Gede Astawa Karang, Center for Environmental Remote Sensing, Chiba University, \\ 1-33 Yayoi-cho, Inage-ku, Chiba-shi 263-8622, Japan, Tel: 81-043-290-3836; Center for Remote Sensing and \\ Ocean Science (CReSOS), Udayana University, PB Sudirman Street, Denpasar 80232, Bali, Indonesia. Tel: \\ 62-361-256-162. E-mail: gede_karang@graduate.chiba-u.jp
}

Received: February 4, 2012 Accepted: February 15, 2012 Online Published: May 17, 2012

doi:10.5539/esr.v1n2p11 URL: http://dx.doi.org/10.5539/esr.v1n2p11

\begin{abstract}
Numerous packets of internal waves were revealed in Advanced Land Observing Satellite Phased Array L-band Synthetic Aperture Radar (ALOSPALSAR) images of the Lombok Strait area, and high-resolution and quick look images were used for their detection and analysis. The parameters of internal waves, such as the number of waves in a packet, crest length, and propagation velocity were estimated from the images. This paper describes the use of PALSAR imagery for internal wave frequency detection and presents the results of a survey that detected 90 internal wave occurrences with ScanSAR and Fine Mode PALSAR imagery over the period May 2006 to April 2011. The paper also discusses the spatial and temporal distribution of internal wave occurrences in the Lombok Strait area.
\end{abstract}

Keywords: ALOSPALSAR, internal waves occurrences, Lombok Strait, spatial and temporal distribution

\section{Introduction}

The ability of Synthetic Aperture Radar (SAR) to detect and measure oceanic internal waves has been widely proven since the launch of SEASAT in 1978 and launch of both the USSR Almaz-1 space station and the European Remote Sensing Satellite (ERS-1) in 1991. SAR observes the ocean surface waves within a broad swath with a spatial resolution from medium to high, which cannot be realized by in-situ measurements. SAR instruments, operating at wavelengths from $21 \mathrm{~cm}$ (L-band) to $3 \mathrm{~cm}$ (X-band), cannot measure internal waves directly because the depth of penetration of radar signals into saline seawaters does not exceed several millimeters. However, the variable currents associated with internal waves modulate the sea surface roughness, which in turn modulates the intensity of backscattered radar signals (Alpers, 1985; Mitnik \& Alpers, 2000). Internal waves cause a pattern of converging and diverging current under the sea surface. These converging places causes the sea surface roughness increased and gives bright bands on SAR images. At diverging places the sea surface is smooth and gives dark bands on the SAR images. Internal waves occur in the World Ocean and are generated by an interaction of bathymetry, water stratification, and current flow. The evolution of internal waves may also make a significant contribution to internal oceanic mixing and, hence, have an important influence on climate change. For these reasons, the importance of scrutinizing the interaction of internal waves with the bottom topography is clear (Chen, 2012).

The use of SAR imagery for internal wave detection in the Lombok Strait area has been presented in several recent studies (Mitnik et al., 2000; Susanto et al., 2005; Mitnik, 2006; Karang et al., 2011). These studies demonstrated the utility of C-band SAR imagery acquired by the European Remote Sensing satellites (ERS-1, ERS-2, and Envisat) for the detection and parameter estimation of internal waves. From January 2006 to March 2011, numerous images over the Lombok Strait were acquired by L-band polarized SAR PALSAR onboard the ALOS satellite. PALSAR allows the study of dynamic oceanic phenomena, such as internal waves and fronts, in a broad range of spatial scales due to the availability of various regimes differing in swath width $(70-350 \mathrm{~km})$ and in ground resolution (from 7-10 to $100 \mathrm{~m}$ ) (Rosenqvist et al., 2004). In this study, the ALOS-PALSAR 
images of the Lombok Strait area with the surface imprints of nonlinear internal waves are considered, and the characteristics of their spatial-temporal variability are presented.

\section{The Physical Oceanography of Lombok Strait}

The Lombok Strait (Figure 1) separates the Bali Island and the Lombok Island. This strait is an important pathway for water transport from the Pacific Ocean into the Indian Ocean and is a part of the Indonesian throughflow (ITF). The length of the Lombok Strait is approximately $60 \mathrm{~km}$, with a contrasting bathymetry along the strait from north to south. The depths in the north are typically between 800 and $1000 \mathrm{~m}$. A shallow sill is found at the southern outlet, where the channel is divided in two by the small Nusa Penida Island. The channel at the western part of this island (Badung Strait) is shallower, with a depth less than $100 \mathrm{~m}$. Right of this island is deeper and has an extremely irregularly shaped sill with a sill-crest depth of approximately $250 \mathrm{~m}$ (Susanto et al., 2005) and a length of $18 \mathrm{~km}$, connecting islands of Nusa Penida and Lombok. Figure 2 shows a depth cross section of the Lombok Strait in the south to north direction. Depth increases from a minimal depth of $250 \mathrm{~m}$ at the sill to $1500 \mathrm{~m}$ in the Flores Sea. This sill is of great importance for the oceanographic behavior in the Lombok Strait. The highest current velocities are observed at the sill where a cross-sectional area of the strait, which bounds the transport of water through the strait, is minimal.

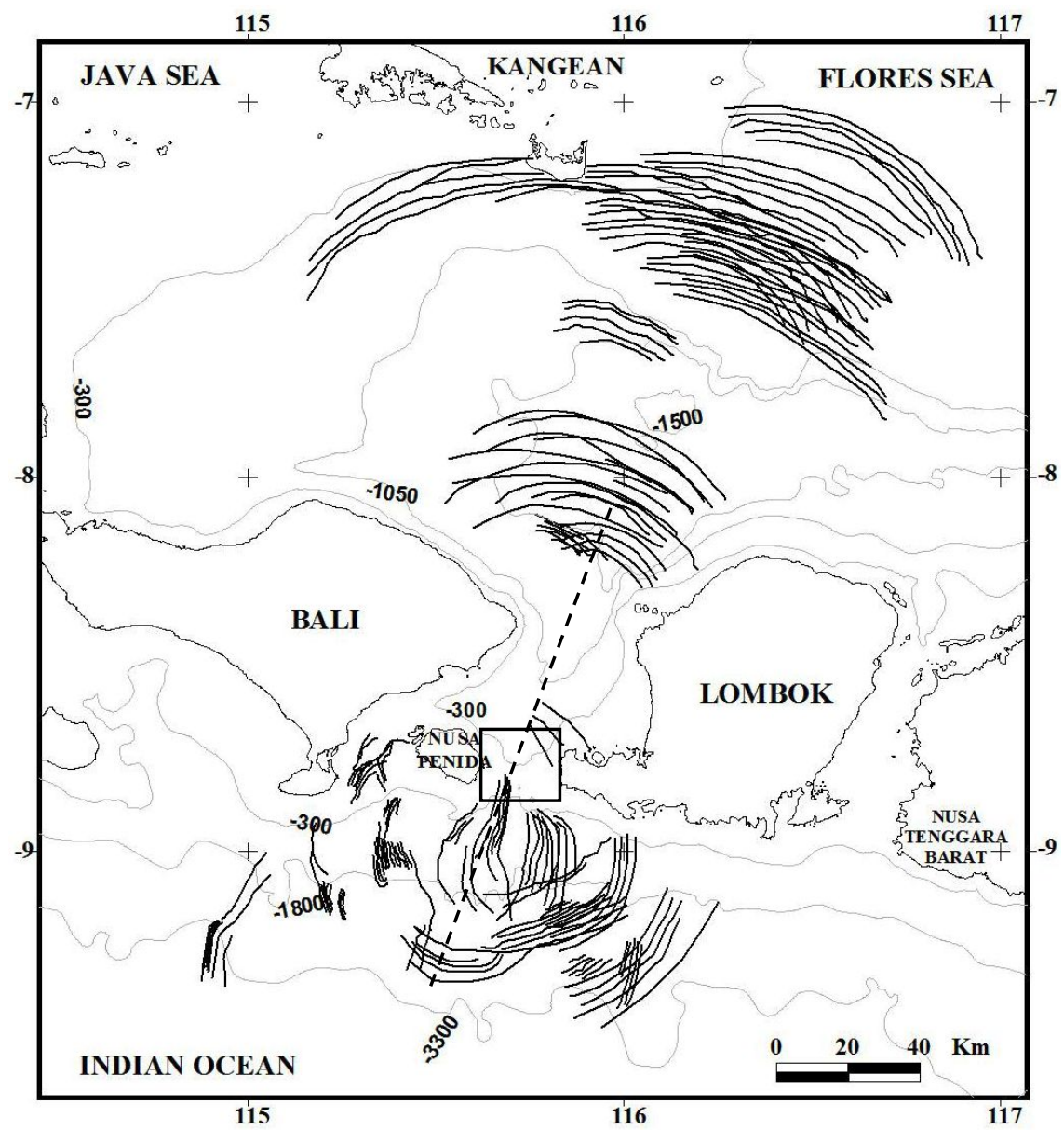

Figure 1. A map of the study area. The numbers on the isobaths are in meters. The bold lines represent crests of internal waves revealed on the PALSAR images. The rectangular box in the center defines an internal wave generation source region to be further analyzed in section 4 . The dashed line is the south-north cross section shown in Figure 2

The ocean current pattern consists of the superposition of the main current flow and tidal currents. The tides in the Indonesian Seas are largely produced by tidal wave propagation from the Pacific and Indian Oceans (Schiler, 2004; Karang et al., 2010). Thus, the tide in the Lombok Strait is produced by tidal waves from the Indian Ocean. 
The semi-diurnal tide, with a period of 12.4 hours, is predominantly at the sill, with a maximal tidal velocity of approximately $\pm 3.5 \mathrm{~m} / \mathrm{s}$ (Murray \& Arief, 1988; Murray et al., 1990). On other side, that is, the northern part of the strait (approximately $50 \mathrm{~km}$ from the sill) the tidal velocity ranges from 0.2 to $0.5 \mathrm{~m} / \mathrm{s}$ (Murray, 1988). The current velocity is also controlled by water column stratification. Sometimes the current velocity in the near surface even has an opposite direction to the current below or near the bottom, which is evidence of a division of the fluid in different layers. To the north of Lombok, the available density profiles show a large density gradient in the upper $300 \mathrm{~m}$ (Murray et al., 1990). The density difference between the upper and lower layers is caused by the difference in salinity and temperature. For example, two layers are observed in the Flores Sea: a high salinity layer at a depth of $150 \pm 20 \mathrm{~m}$ and a low salinity layer at 320-300 $\mathrm{m}$ (Murray at al., 1990). The interface of a two-layer fluid, the pycnocline, is defined by the normal modes of the fluid. This interface is usually defined at the place where the first internal mode has its maximal vertical velocity. In the northern area, this interface is located at a depth of 280 meters, where $1020 \mathrm{~kg} / \mathrm{m}^{3}$ (Figure 2) densities near the surface are observed. Because the water in the Indian Ocean is colder (Figure 2) than water in the Flores Sea, which comes from the Pacific, much higher values of the surface density $\left(1022 \mathrm{~kg} / \mathrm{m}^{3}\right)$ in the southward part of the Lombok Strait are observed. The warm upper layer, which enters the Indian Ocean over the sill, causes a much greater density difference south of the sill.

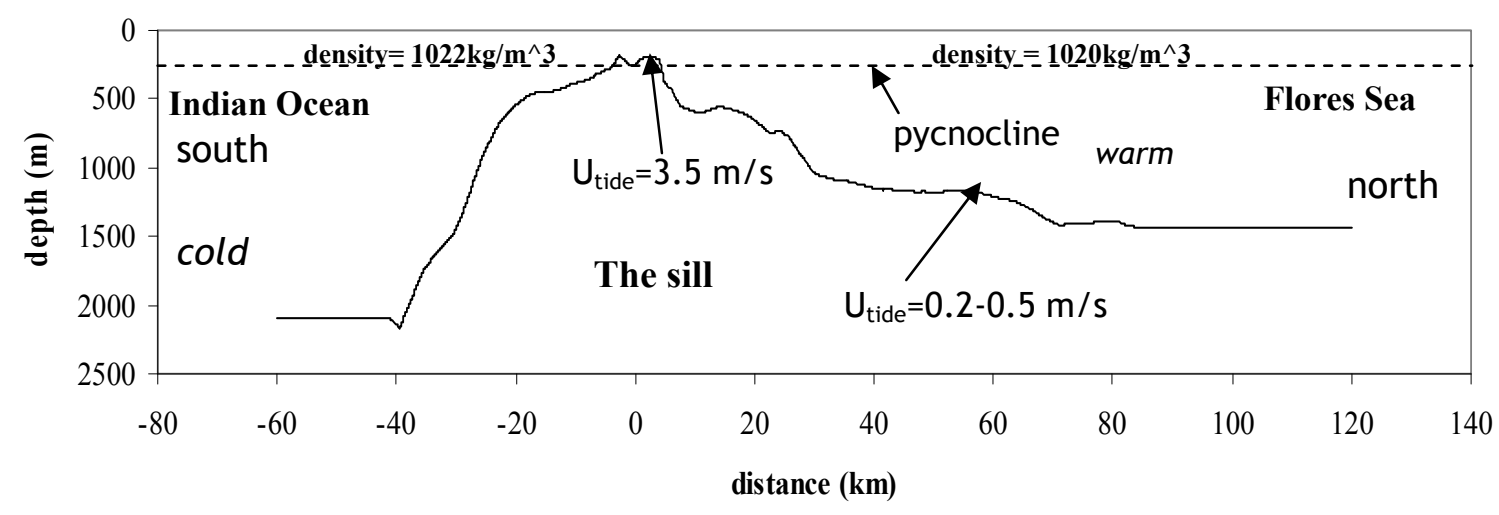

Figure 2. South-north cross section of the bottom topography of the Lombok Strait and water properties

Robertson and Ffield (2005) by numerical simulation show that Lombok Strait is suitable place for internal tides generation. By the narrow channel and shallow sill in the strait the current velocity rapidly increased causes the displacement of the pycnocline area for the generation of internal waves (Jackson, 2007). The nonlinear solitary waves were found to be generated by tidal current and topography interactions in the sill area with propagation velocity of $1.8-1.9 \mathrm{~m} / \mathrm{s}$, as estimated by the analysis of nonlinear wave packets revealed in ERS-1/2 SAR images (Mitnik et al., 2000). However by using the same SAR images combined with in-situ data the behavior of internal waves controlled by Lombok Strait water circulation also investigated (Susanto et al., 2005). They suggested that the emergence of internal waves and their propagation influenced by the variability of tides and water stratification associated with ITF circulation.

\section{Dataset}

The Phased Array L-band Synthetic Aperture Radar, PALSAR, is one of three instruments onboard the ALOS satellite. Having a steerable beam and scan modes with a choice of co-polarization (Horizontal-Horizontal, HH or Vertical-Vertical, VV) and cross-polarization (HV or VH), PALSAR is an advanced version of Japanese Earth Resources Satellite 1, JERS-1, SAR (Nemoto et al., 1991). PALSAR has the following three observation modes: Fine Mode, ScanSAR mode and Polarimetric Mode. The Fine Mode is the most commonly used under regular operation, and its maximum ground resolution of $7 \mathrm{~m}$ is among the highest, as SAR is loaded on a satellite (ERSDAC, http://www.ersdac.or.jp). The ScanSAR mode enables switching of the off-nadir angle from 3 to 5 times to cover a wide area from $250 \mathrm{~km}$ to $350 \mathrm{~km}$ with a ground resolution of 70 to $100 \mathrm{~m}$. The Polarimetric Mode can simultaneously receive horizontal and vertical polarization per each polarized transmission. Table 1 provides an overview of the ALOS PALSAR characteristics (Shimada, 2002). 
Table 1. PALSAR Characteristic

\begin{tabular}{ccccc}
\hline Mode & & Fine & ScanSAR & Polarimetric \\
\hline Center frequency & & \multicolumn{1}{c}{ L-band (1270 MHz) } & \\
\hline Chirp bandwidth, MHz & 28 & 14 & 14,28 & 14 \\
Polarization & $\mathrm{HH}, \mathrm{HV}$ & $\mathrm{HH}+\mathrm{HV}, \mathrm{VV}+\mathrm{VH}$ & $\mathrm{HH}, \mathrm{HV}$ & $\mathrm{HH}+\mathrm{HV}+\mathrm{VH}+\mathrm{VV}$ \\
Incident angle, deg & $8-60$ & $8-60$ & $18-43$ & $8-30$ \\
Range resolution, $\mathrm{m}$ & $7-44$ & $14-88$ & 100 & $24-89$ \\
Swath width, $\mathrm{km}$ & $40-70$ & $40-70$ & $250-350$ & $20-65$ \\
Bit length, bits & 5 & 5 & 5 & 3 or 5 \\
Data rate, Mbps & 240 & 240 & 120,240 & 240 \\
\hline
\end{tabular}

Fine Mode and ScanSAR images are used in the present study. The images, covering a period of five years, from May 2006 to April 2011, were collected by the Japan Aerospace Exploration Agency (JAXA, https://auig.eoc.jaxa.jp/auigs/top/TOP1000 lnit.do) and the Japanese Earth Remote Sensing and Data Acquisition Center (ERSDAC, http://www.ersdac.or.jp). The PALSAR images of the Lombok Strait were selected from the JAXA archive. Prominent SAR signatures of internal waves were found in the images and are discussed in detail in section 4.1 Statistical analysis of Lombok Strait images was mainly performed using the SAR browse archive maintained by ERSDAC.

\section{Results and Discussion}

\subsection{Prominent PALSAR Signatures of Internal Waves}

This section presents some of the clearest manifestations of internal waves propagating from the sill toward the north and south found in PALSAR images. The PALSAR ScanSAR and Fine mode images show that energetic and prominent internal solitary waves are identified in the Lombok Strait during the whole period (Figures 3-7). In particular, internal wave activity was observed on 21 February and 09 October 2007; on 29 August, 29 November, and 28 December 2010; and on 2 February 2011. The surface imprints of internal waves propagating northward in the Flores Sea (Figures 3-5), southward in the Indian Ocean (Figure 7) or in both directions (Figure 3 ) are clearly visible in the images. These waves are generated through the strong tidal flow over the sill in the south of Lombok Strait (Mitnik et al., 2000). The images show the interaction between sea surface waves and the current due to the internal waves activity.

Dark patches, bands and filaments can be observed in Figures 3-7. Dark features correspond to areas where the surface roughness is reduced due to the presence of surface active films both natural (biogenic) and anthropogenic (oil spills) damping the small-scale roughness, or due to weak wind speeds or wave-current interactions (Jackson \& Aprl, 2004).

In the PALSAR image of 29 August 2010 (Figure 3a), two packets of internal waves was observed propagating northward into the Flores Sea. The distance between the first solitons of packets 1 and 2 is about $\Delta \mathrm{L}=77.8 \mathrm{~km}$. The averaged propagation velocity of $1.74 \mathrm{~m} / \mathrm{s}$ was estimated from relationship $V=\Delta \mathrm{L} / \mathrm{T}$, where $T=12.4$ hours is the semidiurnal tidal period. The length of the arc-like crest line of the leading wave exceeds $100 \mathrm{~km}$, as also observed by Susanto et al. (2005). Packets 1 and 2 consist of approximately 9 and 5 solitons, respectively. The crest separation lengths or wavelengths of packet 1 decrease from the front to the rear from approximately $6 \mathrm{~km}$ to $4.1 \mathrm{~km}$ (see the backscatter values profile $\mathrm{K}$ to $\mathrm{K}^{\prime}$ in Figure $3 \mathrm{~b}$ ). For packet 2, the wavelength between successive waves decreases monotonically from approximately $5.5 \mathrm{~km}$ to $3.4 \mathrm{~km}$ (see the backscatter values profile $\mathrm{M}$ to $\mathrm{M}^{\prime}$ in Figure $3 \mathrm{~b}$ ). Also a smaller packet of internal waves south of Lombok Strait propagating into the Indian Ocean was observed on this image. Approximately 4 solitons are observed in packet 3; their wavelengths decrease from approximately $4 \mathrm{~km}$ to $1.5 \mathrm{~km}$ from the front to the rear (see the backscatter values profile $\mathrm{N}$ to N' in Figure $3 \mathrm{~b}$ ). 


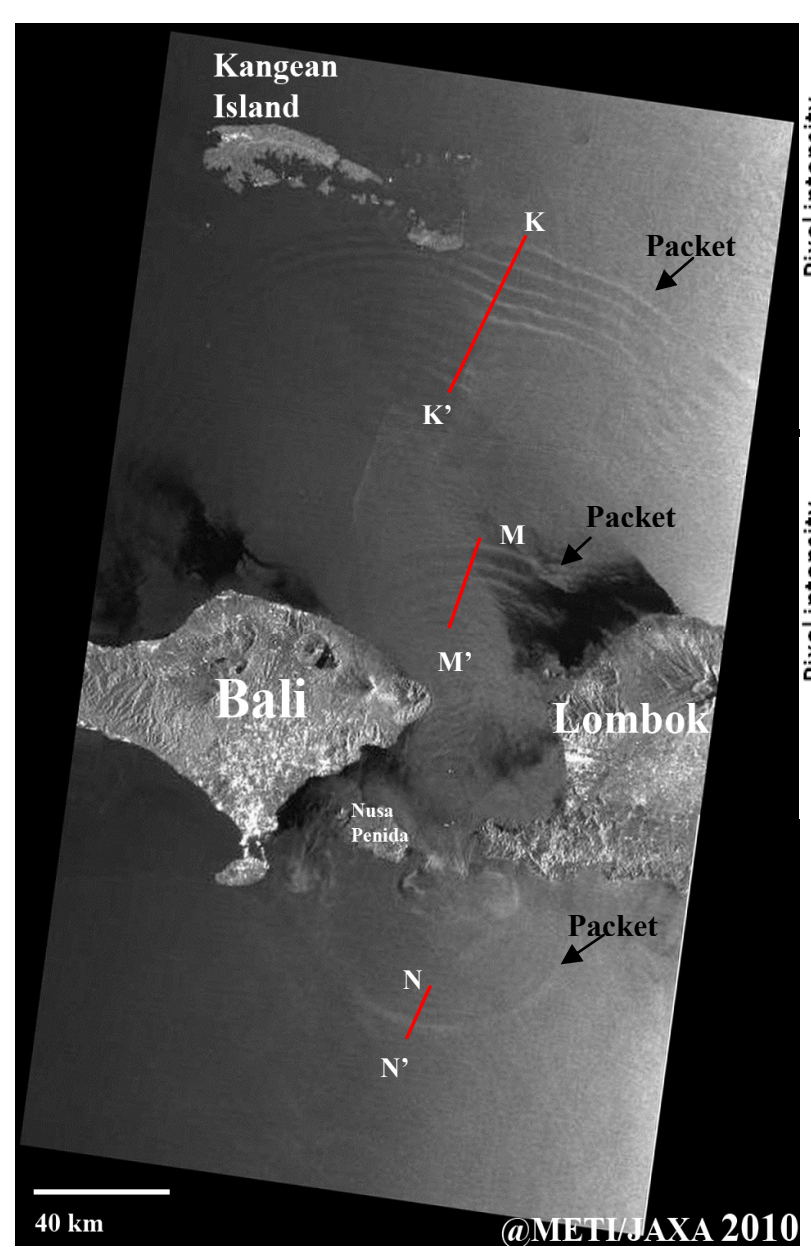

(a)
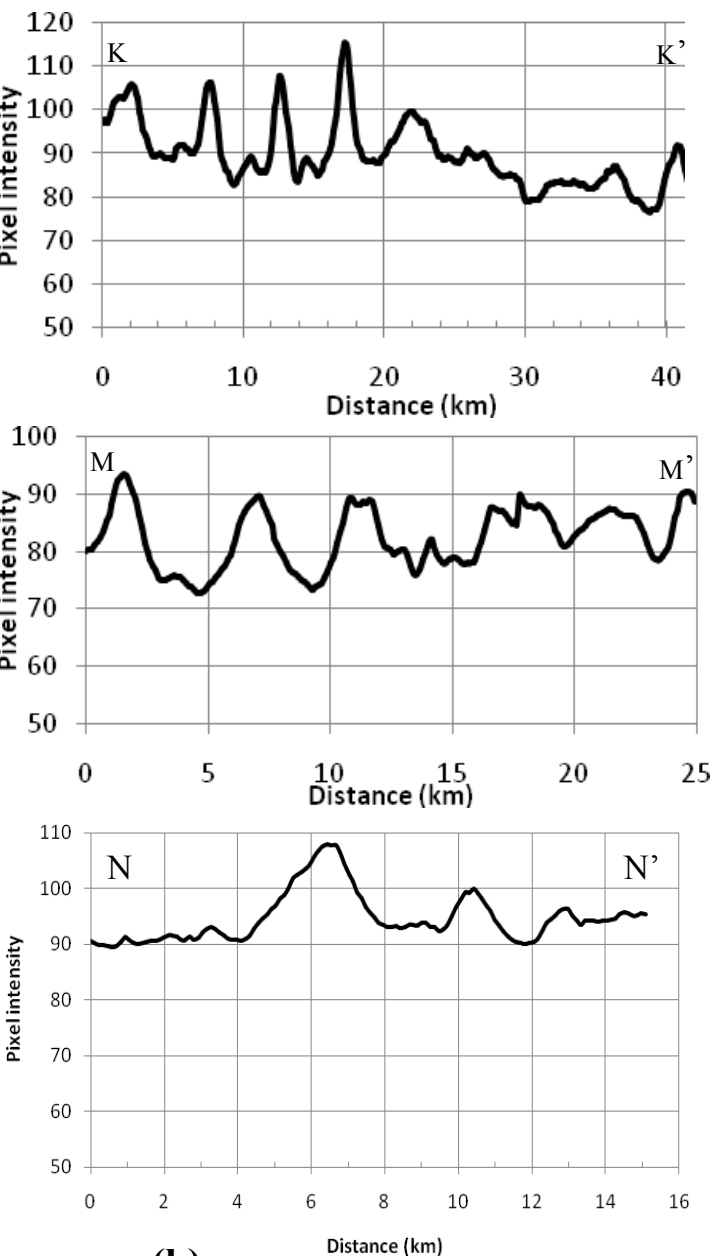

(b)

Figure 3. (a) SAR images of the Lombok Strait acquired on 29 August 2010 at 02:22:50 UTC (a) by the PALSAR ScanSAR mode. (b) Plot of cross profile along sections marked by a red line in KK', MM' and NN', respectively. In Figure 3a, three packets of internal waves are visible in the Lombok Strait area, two propagating north toward Kangean Island and one packet propagating south toward the Indian Ocean. Images (C) from the METI/JAXA

One clear packet of internal solitons in the Flores Sea was observed in the image acquired on 29 November 2010 (Figure 4a). Several waves of the packet reached the shallow water region around the Kangean Islands approximately $200 \mathrm{~km}$ from the sill where the coral reef is situated. Radar contrast of the individual waves in packet against the background depends on variations of sea surface currents accompanying of particular wave and on variations of the sea surface wind (sea surface roughness) which determine the brightness of the background. The first wave of the packet 1 is approximately $101.5 \mathrm{~km}$ away from the packet 2 , and thus, the mean velocity is approximately $2.27 \mathrm{~m} / \mathrm{s}$. Unlike the unclear packet 2, packet 1 consists of 5 solitons. The waves of packet 1 are characterized by a narrow, bright band. Propagation of intense internal waves in the areas with weak winds (they look dark in SAR images) is accompanied by appearance of bands of steep surface waves, their breaking and foaming that explains their bright tone (Figure 4b). Pixel intensity profile between points $\mathrm{O}$ and O' (Figure 4c) illustrates high radar contrast of internal waves crests against the dark background. The average wavelengths of this packet are approximately $4.95 \mathrm{~km}$. The internal wave packet which was generated by the next tidal wave in $12.4 \mathrm{~h}$ has the low contrast the gray-tone background that hinders the location of the first wave in this packet and estimate of the propagation velocity. 

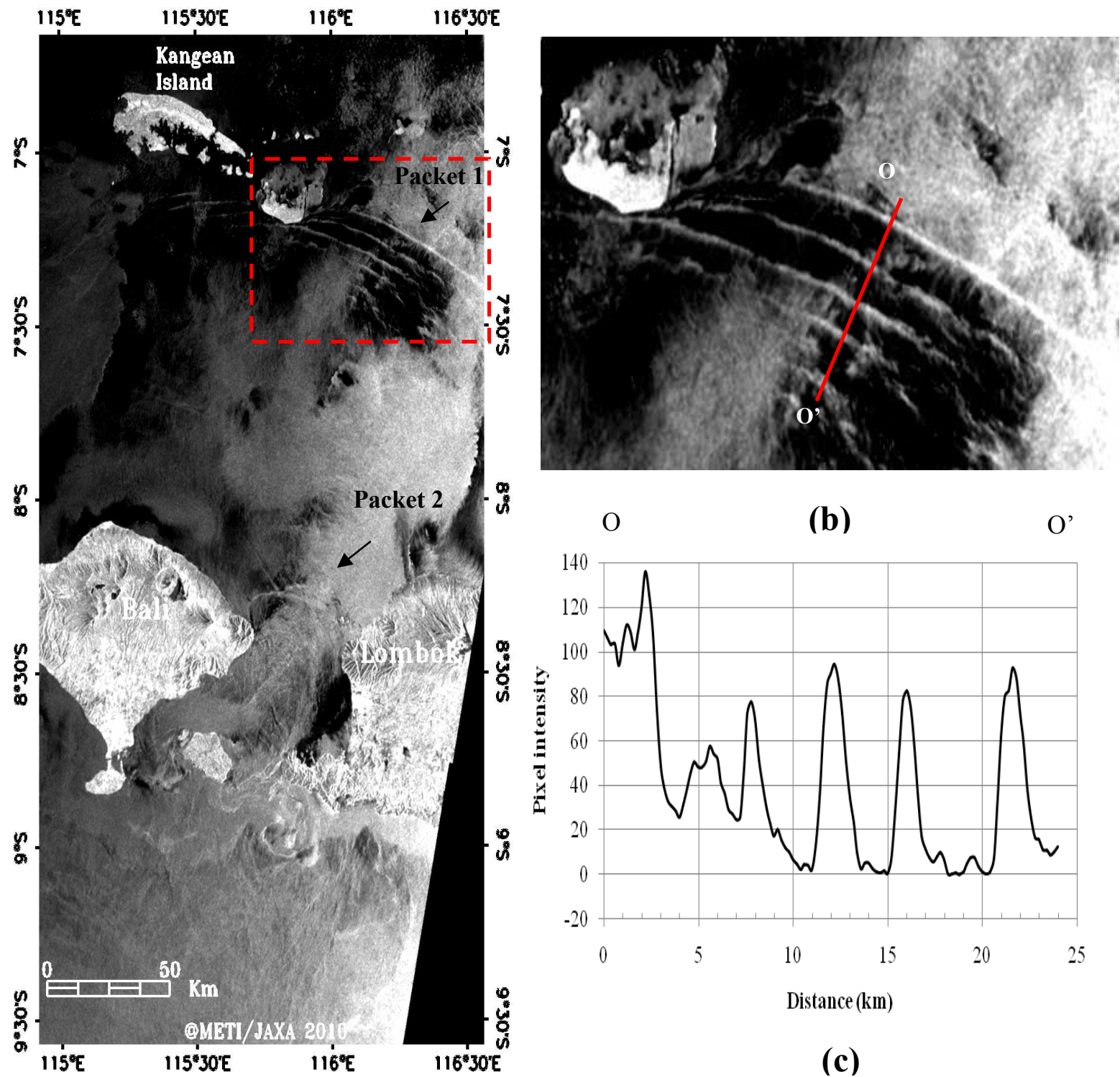

(a)

Figure 4. (a) PALSAR ScanSAR mode images of the Lombok Strait and adjacent area acquired on 29 November 2010 at 02:20:53 UTC; (b) enlarged fragment of the image shown by red rectangle in (a); (c) profile of radar backscatter along transect OO' indicated by a red line in the image. In Figure 4a, two packets of internal waves are propagating north toward the Kangean Islands. Images $\mathbb{C}$ from the METI/JAXA

In the PALSAR images taken on 28 December 2010, several solitons crossed the Kangean Island and some coral reefs. The southern part of the Lombok Strait is not observed in these PALSAR images. In Figure 5a, the northward-propagating waves contain two packets of solitons. The number of waves in Packet 1 reached 12; with wavelengths ranging from $0.5 \mathrm{~km}$ up to $5 \mathrm{~km}$ (see Figures $5 \mathrm{~b}$ and $5 \mathrm{c}$ ). Packet 2 consists of more than 25 solitons with a average wavelength of $4.5 \mathrm{~km}$. Both packets have semi-circular patterns. The first wave of packet 2 is approximately $200 \mathrm{~km}$ from the sill reached a shallow topography eastward of the Kangean Islands. 


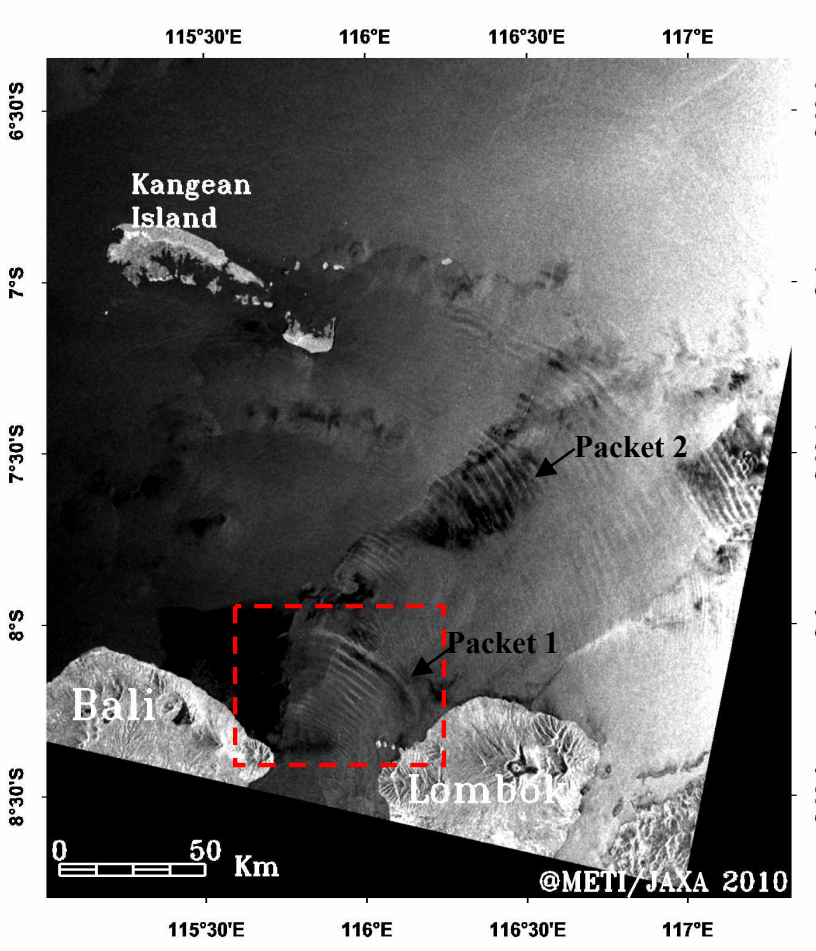

(a)

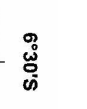

๓ั่

(b)

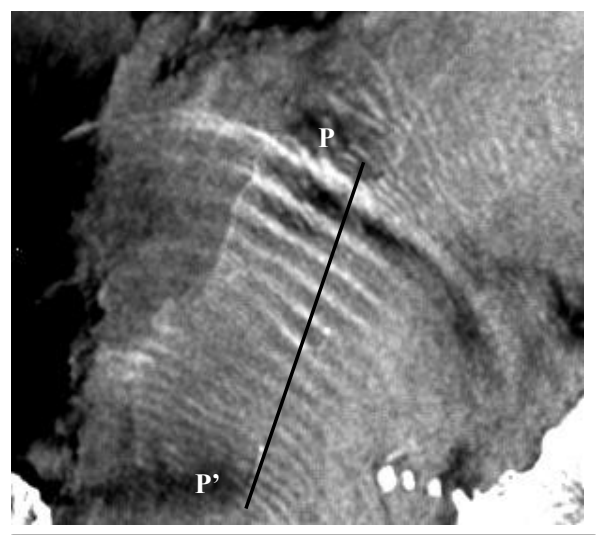

$\stackrel{\circ}{\wp}$

(c)

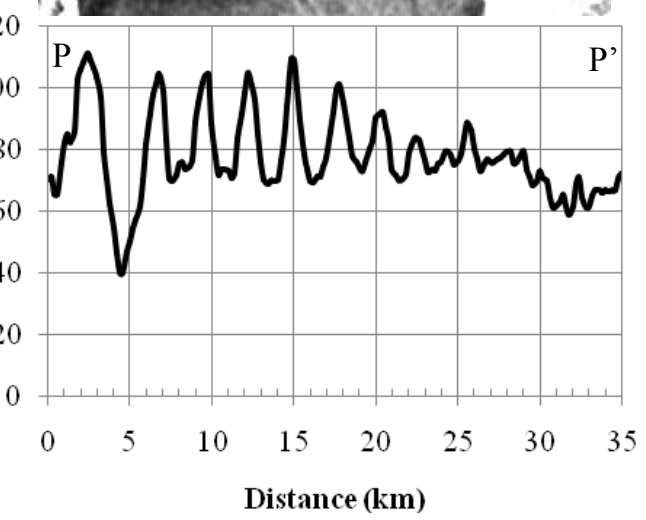

Figure 5. (a) PALSAR from ScanSAR mode images over the northern Lombok Strait acquired on 28 December 2010 at 02:15:27 UTC; (b) enlarged fragment of the image shown by a red rectangle in (a); (c) profile of radar backscatter along transect PP'. The internal waves of the two packets are visible north of the Lombok Strait in Figure. 5a. Packet 1 propagates to the north and the other packets to the northeast. Images $\mathbb{C}$ from the METI/JAXA

Figure 6a presents a weak radar signature of internal waves. This image was acquired on 2 February 2011 at 02:16:42 UTC and shows a weak-scale soliton. Five packets of internal waves are visible north of the Lombok Strait in Figure 6a. Three packets (packets 1,2 and 3) with 1.5 to $5 \mathrm{~km}$ wavelength are originates from the Lombok sill and propagating to the north reached the Kangean Island and Flores Sea. Two packets (packets 4 and 5) propagating to the northwest are also visible in the image. The actual generation location and mechanism for these internal waves (packets 4 and 5) are still unknown, but we suppose that the generation of these packets is related to some local bathymetry-tides interaction in the Flores Sea. The surface imprints of the solitons from the succeeding tide are visible as low contrast semi-circular bands to the north of the Lombok Strait. The distance between the leading solitons in the two wave packets is approximately 84 to $104 \mathrm{~km}$ and, thus, the propagation velocity is approximately 1.8 to $2.3 \mathrm{~m} / \mathrm{s}$, respectively. The leading soliton of packet 3 is located at a distance of approximately $280 \mathrm{~km}$ from the sill, reaching the other two packets internal waves (packets 4 and 5 which propagating to the northwest). 


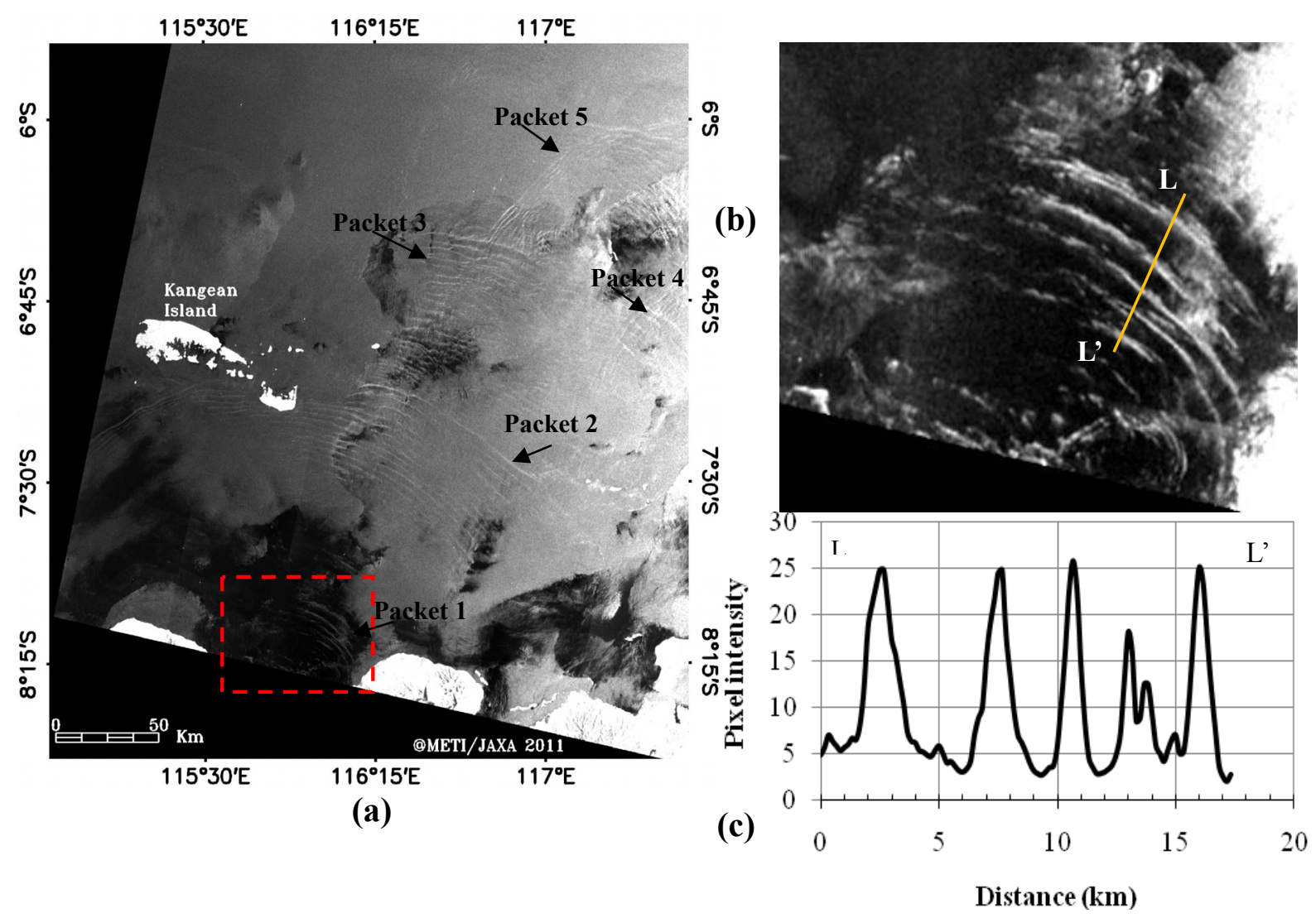

Figure 6. (a) PALSAR from ScanSAR mode images over the northern Lombok Strait area acquired on 2 February 2011 at 02:16:42 UTC; (b) the enlarged fragment of the image shown by a red rectangle in (a); (c) profile of the radar backscatter along transect LL' indicated by a red line in the image. Images $@$ from the METI/JAXA

The sea surface manifestations of the irregular internal waves are also visible in the images taken in high spatial resolution from the PALSAR Fine Mode imagery. The images were taken in the middle of winter (21 February 2007 at 15:09:26 UTC, Figure 7a) and late of summer (09 October 2007 at 15:02:00 UTC, Figure 7b). In addition to an internal wave feature, well-developed thermal plume can be found in the image due to the intrusion of warm Pacific water from the Flores Sea into the Indian Ocean. This intrusion also corresponds to the measurements of the water transport of the Lombok Strait throughflow. The mean annual transport measured with current meters in 1985 was $1.7 \mathrm{~Sv}$ into the Indian Ocean $\left(1 \mathrm{~Sv}=10^{6} \mathrm{~m}^{3} / \mathrm{s}\right)$. The maximum transport was observed during the summer months or south east monsoon (3.8-4 Sv) and a minimum of $1 \mathrm{~Sv}$ during the west monsoon in the spring (Murray et al., 1988). Thus, at 9 October 2007, approximately 3.8 milliard cubic meters per second of warm Pacific water was transported through the Lombok Strait. 

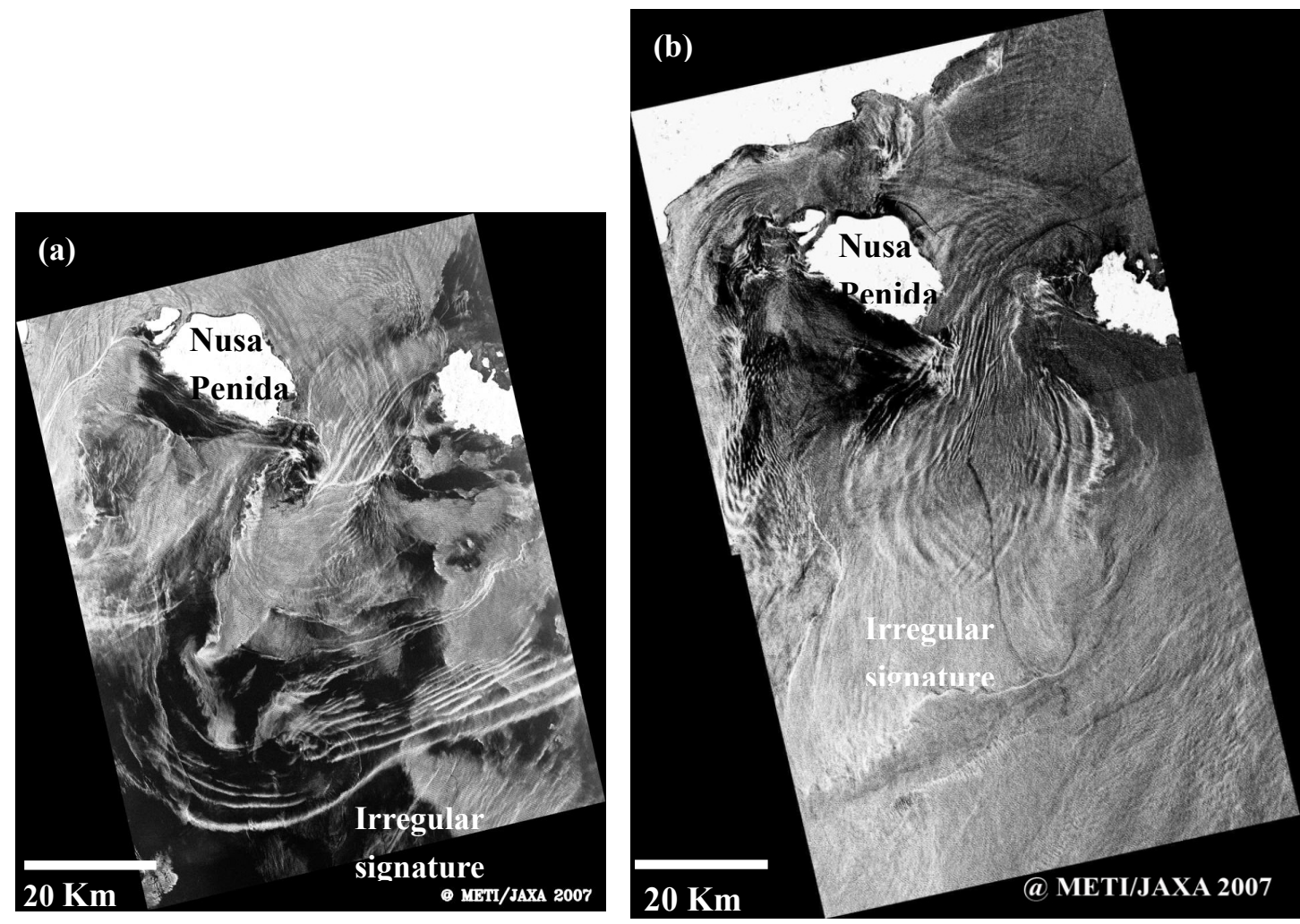

Figure 7. ALOS PALSAR images from Fine Mode acquired on 21 February 2007 at 15:09:26 UTC (a) and 09 October 2007 at 15:02:00 UTC (b). Images $(\mathcal{C}$ from the METI/JAXA

\subsection{Spatial Distribution of Internal Waves}

A selection of 20 ALOS PALSAR images was obtained to study the spatial distribution of internal waves in the Lombok Strait area. The images span most calendar months and were spread out between 2007 and 2011. We created a spatial distribution map by placing all these internal wave packets at their corresponding locations (Figure 1). The results show that the internal wave packets are distributed in the north and south of the Lombok Strait and their origin is the shallow sill located between the Nusa Penida and Lombok islands. This result confirms the previous investigations showing that the internal waves in the Lombok Strait are generated through the strong flow over the sill in the south of Lombok Strait (Mitnik et al., 2000, Susanto et al., 2005 and Ningsih eta al., 2008). The internal solitary waves appear as circular bands frequently observed parallel to the sill with a northward direction. These circular internal waves penetrating to a depth of $\sim 1000$ meters and propagating away toward the Kangean Islands and the Flores Sea. The shallow topography of Kangean Island limits the region of activity of the internal solitary wave propagation from the north mouth of the Lombok Strait to approximately $7.1^{\circ} \mathrm{S}$ latitude.

\subsection{Temporal Distribution of Internal Waves over Lombok Strait by PALSAR during 2006-2011}

The ALOS-PALSAR quick look images were used as a baseline for the temporal variability of the Lombok Strait internal waves. The data covering a period of five years from May 2006 to April 2011 are collected from the ERSDAC, http://www.ersdac.or.jp. A total of 1013 scenes with different Granule ID were examined, of which 673 images were obtained by the Fine Mode and 340 images by the wider-swath ScanSAR mode. A total of 90 images taken on different days with visible internal wave imagery were collected. These records were compiled entirely "by eye" and did not count individual wave packets but rather the distinct daytime wave activity visible in any given image.

For yearly distribution, the PALSAR-observed occurrence frequency is defined as

$$
f_{i y}=\frac{N_{i}}{N_{y}} x 100 \%
$$


where $N_{i}$ is the number of total days on which the internal waves were imaged by PALSAR; here, $i(y)$ represents the $i$ th (jth) year. Tables 2 and 3 shows the PALSAR images distributed over Lombok Strait.

Table 2. Yearly distribution of PALSAR images over Lombok Strait

\begin{tabular}{lcccccc}
\hline & 2006 & 2007 & 2008 & 2009 & 2010 & 2011 \\
\hline No. of SAR data & 13 & 41 & 48 & 27 & 55 & 17 \\
No. of internal wave occurrence & 7 & 22 & 17 & 11 & 28 & 5 \\
\hline
\end{tabular}

Table 3. Monthly distribution of PALSAR images over Lombok Strait

\begin{tabular}{lrrrrrrrrrrrr}
\hline & Jan & Feb & Mar & Apr & May & Jun & Jul & Aug & Sep & Oct & Nov & Dec \\
\hline No. of SAR data & 18 & 17 & 18 & 9 & 11 & 17 & 18 & 20 & 23 & 20 & 14 & 16 \\
No. of internal wave occurrence & 8 & 9 & 9 & 4 & 6 & 6 & 9 & 11 & 8 & 7 & 6 & 7 \\
\hline
\end{tabular}

Figure 8 shows the yearly distribution of internal waves over the Lombok Strait. We can see that the results give an interannual variability of PALSAR-observed internal wave occurrence frequency in the Lombok Strait. The frequencies are higher in 2006, 2007 and 2010 than in other years. This interannual variability implies that there are long-term and large-scale processes that play a role in modifying internal wave occurrence frequency and SAR imaging in the Lombok Strait and adjacent areas. The ITF transports relatively warm water from the Pacific into the Indian Ocean, is important element that may influence the SAR-observed internal wave occurrence frequency in the Lombok Strait area. Previous investigations have found that the ITF is regulated by intraseasonal (Arief \& Murray, 1996) and interannual (England \& Huang, 2005) influences, with the latter a function of the El Niño Southern Oscillation (ENSO) (Mathews et al., 2011). These circulations directly contribute to the variations of the sea water condition from the surface to the bottom.

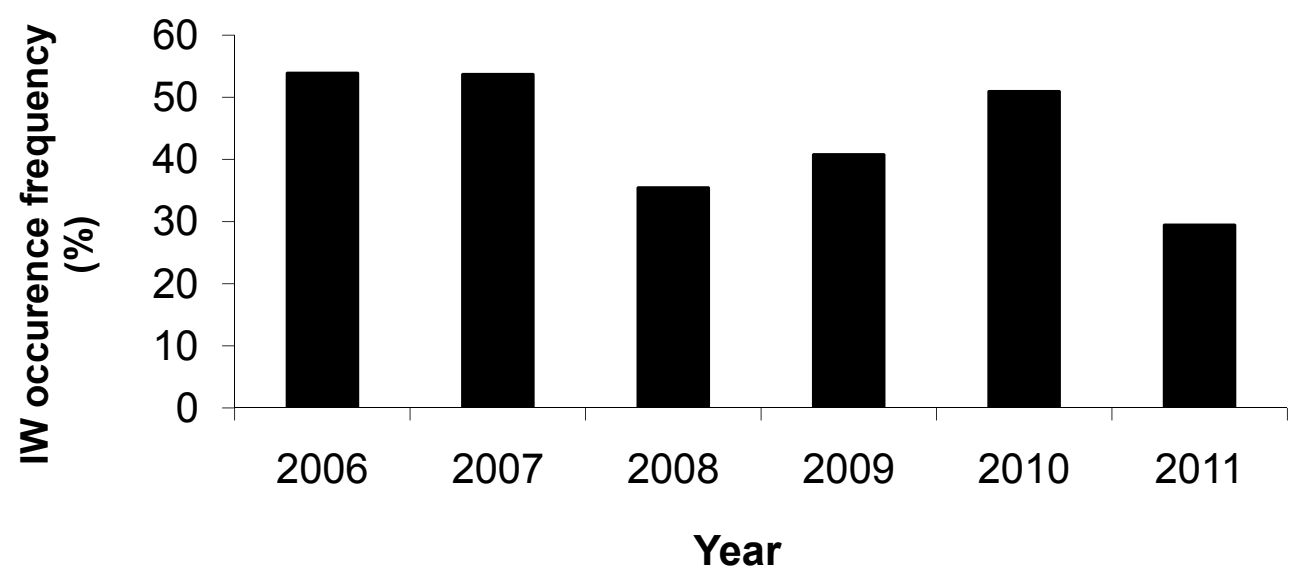

Figure 8. Yearly distribution of SAR-observed internal wave occurrence frequency in the Lombok Strait

For monthly distribution, the PALSAR-observed occurrence frequency is defined as

$$
f_{i m}=\frac{n_{i}}{n_{m}} x 100 \%
$$

where $n_{i}$ is the number of total days in the $i$ th $(m$ th) month of 6 years, at which the internal waves were acquired. The monthly distributions of the PALSAR-observed internal waves in the Lombok Strait are shown in Figure 9. We can see that the results give a seasonal variability. The high occurrence frequencies are distributed in February, May and August. The low occurrence frequencies are distributed in late summer, from September to October, and in June. The other months appear to be transition periods. 


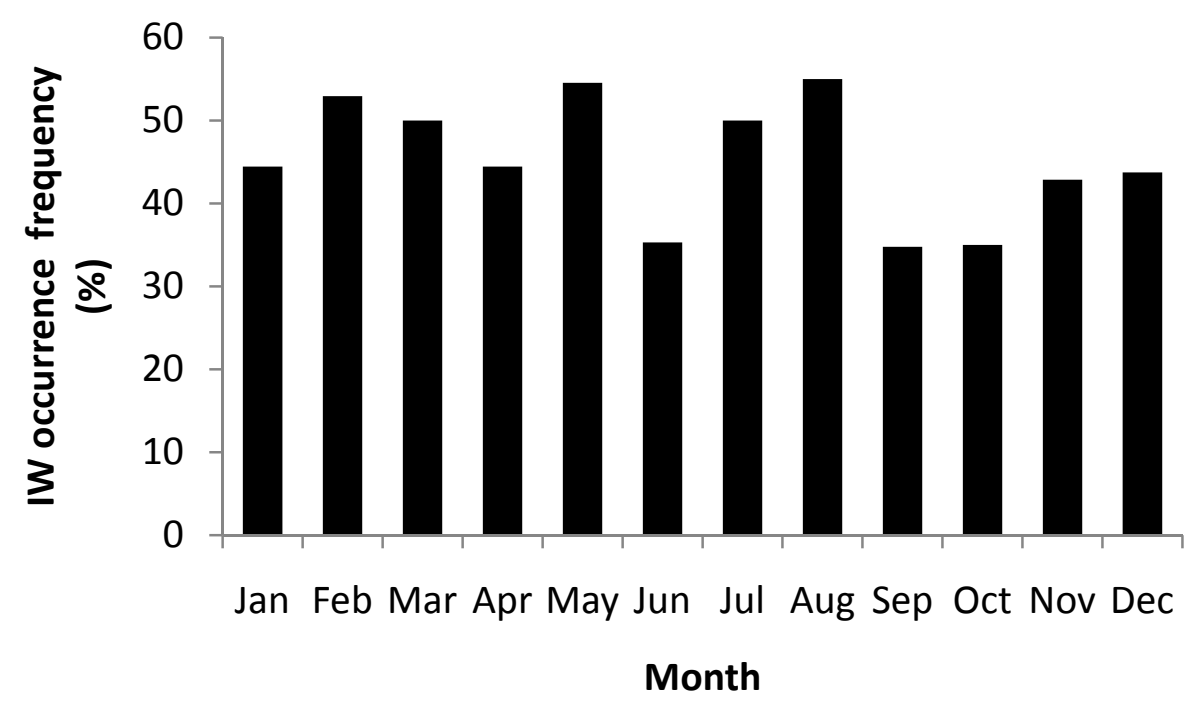

Figure 9. Monthly distribution of SAR-observed internal wave occurrence frequency in Lombok Strait

\section{Summary}

An attempt has been made to understand the characteristic of internal waves in the Lombok Strait area. The intense of internal waves generation in this area due to its geometry and the tidal flow associated with ITF. ALOS PALSAR, with its combined attributes of fine resolution, medium to large swath area, and ready image access (for quick look images) allowed a survey of spatial and temporal distributions of internal wave occurrences in the Lombok Strait. Analyses of the PALSAR images showed that the internal waves are generated in the central Lombok sill then propagate away into the north and south directions. Information on the type of modulation, wavelength, propagation velocity, direction of propagation and crest length of the internal waves can be immediately obtained from the images.

A survey of ScanSAR and Fine Mode PALSAR imagery acquired between May 2006 and April 2011 found 90 internal wave occurrences within a latitudinal band from $7.26^{\circ}$ to $9.83^{\circ} \mathrm{S}$ and a longitudinal band from $115.06^{\circ}$ and $116^{\circ} \mathrm{E}$. The yearly distribution of SAR-observed internal wave occurrences indicates that the frequencies in 2006, 2007 and 2010 are higher than other years. This interannual variability reveals that there are great physical processes that play a role in modifying internal wave occurrence frequency in the Lombok Strait area. Interannual adjustments of thermocline structures in the Lombok Strait, as well as the behavior of the Indonesian throughflow, monsoons, and ENSO, are counted as great circulation processes. The monthly PALSAR-observed occurrence frequency shows that the high occurrence frequencies are distributed in February, May and August, with a maximum frequency of $55 \%$ in August. The low occurrence frequencies are distributed in June, September and October, with a minimum frequency of $34.8 \%$ in September. Because the visibility of internal waves on the SAR images depends on local environmental factors, there may be some external boundary conditions, such as wind speed and sea state, that will influence its appearance. Further dynamical analyses combined with in situ data are needed to clarify our investigations.

Furthermore, the data of the several remote sensing instruments in the last two decades offers the possibility of building a large database of internal wave activity in a broad area, though it is a great challenge to determine the detailed characteristics and mechanisms of internal wave activity associated with changing time and environmental conditions. Work on the examination of multisensor imagery for internal wave signatures in the Lombok Strait area is ongoing.

\section{Acknowledgments}

The authors would like to thank the JAXA and ERSDAC. The PALSAR scenes obtained from JAXA were provided by the CReSOS, Udayana University. We used the browser archives maintained by the ERSDAC. This research was supported by the Beasiswa Unggulan, Bureau for Planning and International Cooperation, Ministry of National Education and Culture of the Republic of Indonesia and from RFBR project 11-05-ophi-m-2011 


\section{References}

Alpers, W. (1985). Theory of radar imaging of internal waves. Nature, 314, 245-247. http://dx.doi.org/10.1038/314245a 0

Arief, D., \& Murray, S. P. (1996). Low frequency fluctuations in the Indonesian through Lombok Strait. $J$. Geophys. Res., 101(C5), 12455-12464. http://dx.doi.org/10.1029/96JC00051

Chen, C. Yuan. (2012). A critical review of internal wave dynamics. Part 1 - Remote sensing and in-situ observations. Journal of Vibration and Control, 18(3), 417-436. http://dx.doi.org/10.1177/1077546310395971

England, M. H., \& Huang, F. (2005). On the interannual variability of the Indonesian Throughflow and its linkage with ENSO. J. Climate, 18(9), 1435-1444. http://dx.doi.org/10.1175/JCLI3322.1

Jackson, C. R. (2007). Internal wave detection using the Moderate Resolution Imaging Spectroradiometer (MODIS), J. Geophys. Res., 112(C11012), 13.

Jackson, C. R., \& Apel, J. R. (eds) (2004). Synthetic Aperture Radar (SAR) Marine User's Manual, NOAA NESDIS Office of Research and Applications, Washington DC.

Karang, I. W. G. A., \& Nishio, F. (2011). Internal waves in the Lombok Strait revealed by ALOS PALSAR images. Proc. IEEE Intern Geosci.Remote Sensing Symp. IGARSS 2011. Vancouver, Canada. pp. 253-256.

Karang, I. W. G. A., Nishio, F., \& Osawa, T. (2010). Estimation of tidal energy dissipation and vertical diffusivity in the Indonesian seas. Int. J. Remote Sens. Earth Sci., 7, 53-72.

Matthews, J. P., H. Aiki, S. Masuda, T. Awaji, \& Y. Ishikawa. (2011). Monsoon regulation of Lombok Strait internal waves. J. Geophys. Res., 116(C05007), 14.

Mitnik, L. M. (2006). Dynamic phenomena in the Lombok Strait and surrounding waters: imprints on ERS and Envisat SAR images. Earth Observations and Remote Sensing (Issledovanie Zemli iz Kosmosa), 6, 83-92. (in Russian).

Mitnik, L. M. (2008). Advanced Land Observing Satellite PALSAR observations of the oceanic dynamic phenomena in the coastal zone.Proc. IEEE Intern Geosci.Remote Sensing Symp. IGARSS 2008. Boston, Ma, USA.

Mitnik, L., \& W. Alpers. (2000). Sea surface circulation through the Lombok Strait studied by ERS SAR. Pp. 313-317 in Proceedings of the $5^{\text {th }}$ Pacific Ocean Remote Sensing Conference (PORSEC 2000), Vol. I, 5-8. Dec 2000, Goa, India.

Mitnik, L., W. Alpers, \& H. Lim. (2000). Thermal plumes and internal solitary waves generated in the Lombok Strait studied by ERS SAR. Pp. 1-9 in ERS-Envisat Symposium: Looking down to Earth in the New Millenium, 16-20 October 2000. Gothenburg, Sweden. SP-461. European Space Agency, Publication Division, Noordwijk, The Netherlands.

Murray, S. P., \& D. Arief. (1988). Throughflow into the Indian Ocean through the Lombok Strait, January 1985-January 1986. Nature, 333, 444-447. http://dx.doi.org/10.1038/333444a0

Murray, S. P., Arief, D., Kindle, J. C., \& Hurlburt, H. E. (1990). Characteristics of circulation in an Indonesian Archipelago strait from hydrography, current measurements and modelings results. Physical Oceanography of Sea Strait, 318, 3-23.

Nemoto, Y., Nishio, H., Ono, M., Mizutamari, H., Nishioka, K., \& Tanaka, K. (1991). Japanese earth resources satellite-1 synthetic aperture radar. Proc. IEEE, 79, 800-809. http://dx.doi.org/10.1109/5.90159

Ningsih, N. S., Rachmayani, R. Hadi, S., \& Brodjonegoro, I. S. (2008). Internal waves dynamics in the Lombok Strait studied by numerical model. Int. J. Remote Sens. Earth Sci., 5, 17-33.

Robertson, R., \& Ffield, A. (2005). $\mathrm{M}_{2}$ baroclinic tides in the Indonesian seas. Oceanography, 18(4), 62-73. http://dx.doi.org/10.5670/oceanog.2005.06

Schiller, A. (2004). Effects of explicit tidal forcing in an OGCM on the water-mass structure and circulation in the Indonesian throughflow region. Ocean Modeling, 6, 31-49. http://dx.doi.org/10.1016/S1463-5003(02)00057-4

Shimada, M. (2002). User's Guide to NASDA's SAR Products Ver. 3 (NDX-000291). National Space Development Agency of Japan, Tokyo-To, Japan.

Susanto, R. D., Mitnik, L., \& Zheng, Q. (2005). Ocean Internal Waves Observed in the Lombok Straits. Journal of Oceanography, 18(4). 